\title{
A Review of Research on Shear Strength Decay in Members under Load Reversals
}

\author{
Rémy Lequesne and Gustavo Parra-Montesinos
}

Synopsis: Early research on the behavior of frame members subjected to reversed cyclic displacements has been reviewed, with an emphasis on the phenomenon of shear strength decay. Information is provided about variables that affect shear strength decay and measures that can be taken to mitigate this phenomenon, which should be of interest to students and structural engineers learning or involved in earthquake-resistant design of reinforced concrete structures.

Starting in the 1950s, the effect of reversing the loading direction on the flexural response of beams was investigated experimentally. Among other findings, tests showed that single and repeated reversals of load had little influence on flexural strength, but that loading history does influence the deformation capacity and stiffness of members. Although several researchers emphasized the importance of providing adequate transverse reinforcement confining the member core, the role of shear stresses on the response of frame members was not well understood until the early 1970s. Tests by Brown and Jirsa, Wight and Sozen, and Popov, Bertero and Krawinkler, showed that member strength can decay under reversals of load if shear stress demands are large or if inadequate transverse reinforcement is provided. In particular, it was shown by Wight and Sozen that maintaining the integrity of the concrete core through use of closely spaced transverse reinforcement with enough area to resist the entire shear demand without yielding is essential, although not necessarily sufficient. Changes to the ACI Building Code aimed at minimizing shear strength decay were first adopted in 1983 and have remained in subsequent editions of the Code with relatively minor changes.

Keywords: shear, strength decay, beam, column, seismic 
Rémy D. Lequesne, MACI, is Assistant Professor of Civil, Environmental and Architectural Engineering at the University of Kansas. He is Secretary of Joint ACI-ASCE Committee 408, Bond and Development of Steel Reinforcement, and member of ACI Sub-Committee 318-J, Joints and Connections, and Joint ACI-ASCE Committee 352, Joints and Connections in Monolithic Concrete Structures. His interests include earthquake resistant design and the behavior of reinforced concrete and fiber reinforced concrete members.

Gustavo J. Parra-Montesinos, FACI, is the C.K. Wang Professor of Structural Engineering at the University of Wisconsin-Madison. He is a member of ACI Committee 318, Structural Building Code, and Chair of ACI SubCommittee 318-J, Joints and Connections. He is also Chair of Joint ACI-ASCE Committee 352, Joints and Connections in Monolithic Concrete Structures, and member of Joint ACI-ASCE Committee 335, Composite and Hybrid Structures. His research interests include the behavior and design of reinforced concrete, fiber reinforced concrete, and hybrid steel-concrete structures.

\section{INTRODUCTION}

In the design of reinforced concrete earthquake-resisting frame members, it is critical that shear distress be limited in order to ensure acceptable deformation capacity and reduce damage. Accordingly, several ACI Building Code ${ }^{1}$ provisions for beams and columns of frames categorized as "special moment frames" are aimed at minimizing shear distress. Pertinent requirements include using a capacity design approach to calculate demand, neglecting any contribution of the concrete to nominal shear strength in beams, and limiting hoop spacing to one-fourth of the effective (beams) or overall (columns) member depth. These provisions are largely based on findings from early research aimed at understanding the behavior of frame members subjected to cycles of load reversals.

The aim of this paper is to review relevant research on the behavior of frame members under earthquake-type demands, beginning with the first tests of flexural members subjected to fully reversed loads and ending with the $1983 \mathrm{ACI}$ Building Code $^{2}$, as it was the first ACI Code edition to incorporate several provisions aimed at minimizing shear strength decay. This paper describes the basis for pertinent ACI Building Code provisions (other code or design documents were not included in this review), emphasizes the importance of low shear stress demands, and highlights reinforcement detailing options that have been shown to improve member behavior. This review should therefore be of interest to students and structural engineers, particularly those learning or involved in earthquake-resistant design of reinforced concrete structures.

\section{BEHAVIOR OF FLEXURAL MEMBERS UNDER REVERSALS OF LOAD}

The first studies of frame members under reversals of load were focused on their effect on flexural behavior. The specimens were therefore designed so that brittle mechanisms such as shear and bond would not dominate behavior. Findings showed that reversals of load had little effect on flexural strength, but that loading history could influence deformation capacity and reduce member stiffness. Although shear stress demands were often low, the researchers emphasized the importance of preventing shear failures and confining the member core. The following describes pertinent early studies on the flexural behavior of members under load reversals.

\section{McCollister, Siess, and Newmark}

In 1954, McCollister, Siess, and Newmark ${ }^{3}$ reported results from six beam specimens loaded monotonically until failure after previously undergoing a single "push" in the opposite direction. Although this loading history is more representative of a blast than an earthquake (one reversal of load), the study identified several aspects of behavior that are typical of specimens subjected to repeated reversals of load. The specimens, which had a 6 by 12 in. (150 by 300 $\mathrm{mm})$ cross-section, were supported by rollers spaced $9 \mathrm{ft}(2740 \mathrm{~mm})$ apart and loaded through a column stub at midspan (Fig. 1). Because the test setup could only apply force in one direction, the specimens were removed after loading in one direction, inverted, and placed back into the test frame for loading in the opposite direction. To ensure a flexure-dominated response, transverse reinforcement was provided "that would be capable of carrying all of the predicted maximum shear force at a unit stress not in excess of [its] yield point," resulting in specimens that had no shear force attributed to the concrete in design (i.e., $V_{c}=0$, where $V_{c}$ is the shear strength attributed to the concrete).

Figure 2 shows the load versus deflection response of Specimen T-12I, which had previously been loaded in the opposite direction, alongside the result from Specimen T-2, a comparable specimen loaded monotonically to failure 
without a previous push. As shown in Fig. 2, the reversal of load did not significantly influence the strength or deformation capacity of the specimen. However, the preceding loading in the opposite direction did cause the definite yield point observed in the test of Specimen T-2 to be replaced with a gradual change in slope, due to the Bauschinger effect. McCollister, Siess, and Newmark also observed "faulting across nearly vertical cracks near the column stubs. These cracks, which extended throughout the depth of the beams, were developed as a result of tension forces having been present in both the upper and lower sections of the beam." This faulting, frequently referred to as sliding, was most pronounced in specimens loaded to near their maximum flexural strength in one direction prior to reversing the direction of loading.

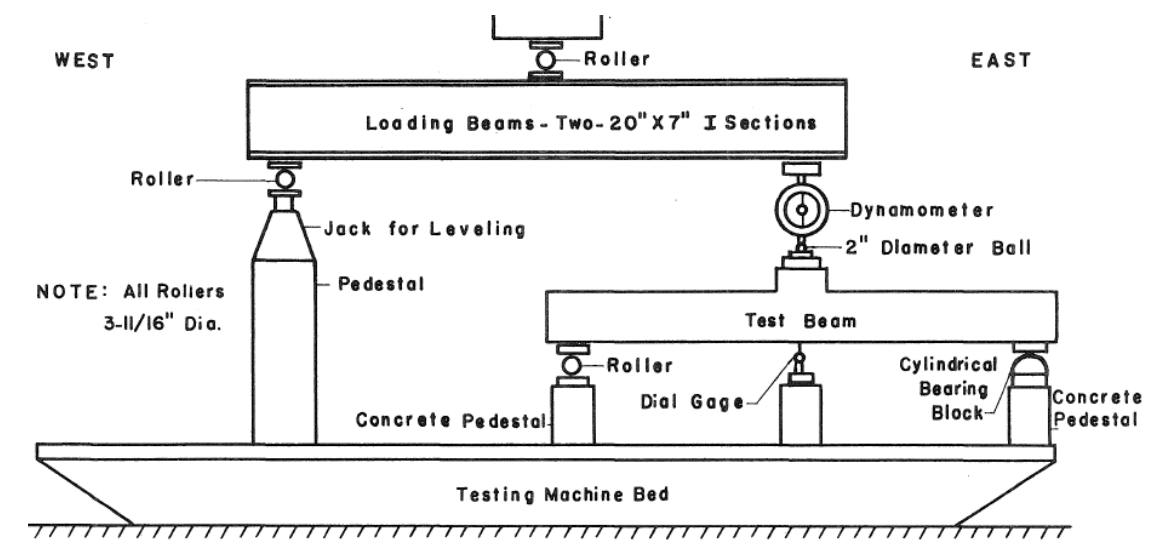

Figure 1 - Schematic of test setup used by McCollister, Siess, and Newmark (Ref. 3).

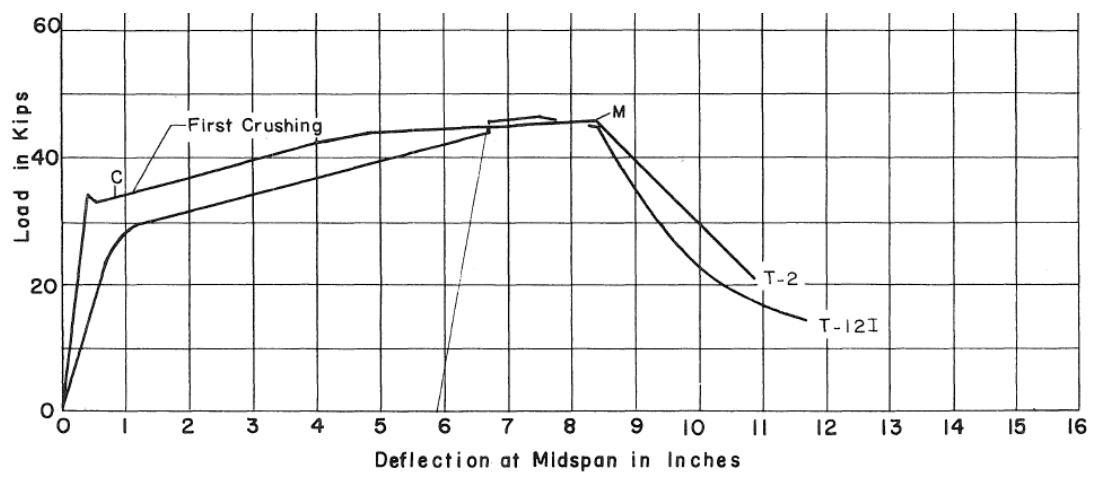

Figure 2 - Load versus deflection for specimens subjected to monotonic (T-2) and reversed (T-12I) loads $($ Ref. 3), 1 kip $=4.45 \mathrm{kN}, 1$ in. $=25 \mathrm{~mm} \approx 2.0 \%$ chord rotation.

\section{Burns and Siess}

As part of an investigation aimed at studying the load-deformation response of beam-column connections, Burns and Siess $^{4,5}$ tested three specimens under repeated and fully reversed loads. The beam specimens, which were 8 in. (200 $\mathrm{mm})$ wide with an effective depth of either 10 or $18 \mathrm{in}$. $(250$ or $450 \mathrm{~mm})$, were loaded through a column stub at midspan and supported by rollers at their ends. The influence of shear on member behavior was minimized by keeping the shear stresses low (below $3 \sqrt{f_{c}^{\prime}}$ [psi], or $0.25 \sqrt{f_{c}^{\prime}}$ [MPa]) and providing enough transverse reinforcement to resist the entire imposed shear without yielding. The force versus deflection response of Specimen J-3 is shown in Fig. 3.

Burns and Siess reported that flexural strength is not significantly affected by load reversals, but that stiffness and deformation capacity may be. With respect to transverse reinforcement, the study found that "closed ties to support the steel as well as to confine the concrete core" are essential, and that when closed ties are provided, "under-reinforced beams possess remarkable ductility." Even though shear stresses were low, Burns and Siess noted that "some members failed with a mode of failure involving shear" that limited the deformability of the specimens compared to specimens 
dominated by flexure. The explanation provided for the failures "involving shear" was that cracks developed at an inclination greater than 45 degrees within the plastic zone that resulted in fewer ties engaged in resisting shear.

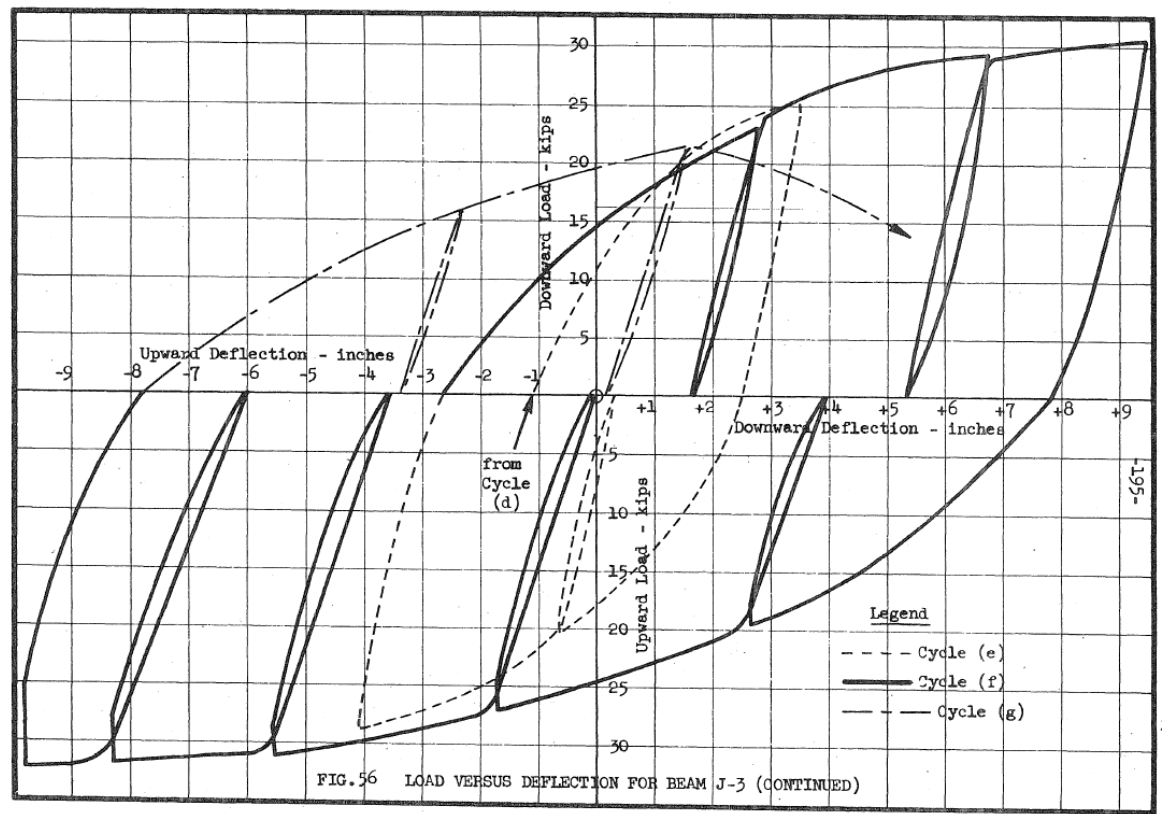

Figure 3 - Load versus deflection for Specimen J-3 (Ref. 4), $1 \mathrm{kip}=4.45 \mathrm{kN}, 1$ in. $=25 \mathrm{~mm} \approx 1.5 \%$ chord rotation.

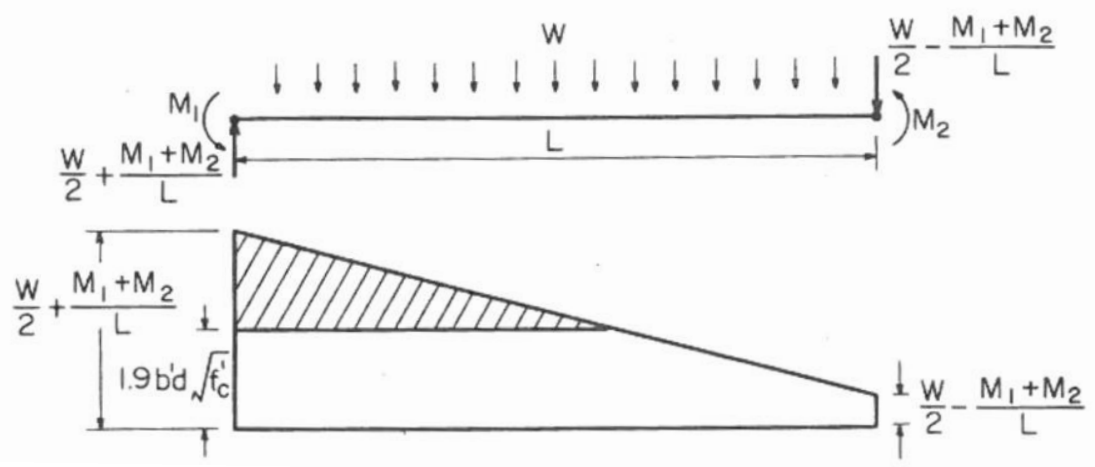

Figure 4 - Shear diagram for a beam developing its moment strength at both ends and gravity load (Ref. 6).

The Blume, Newmark, and Corning book and 1963 ACI Building Code

In 1961, Blume, Newmark, and Corning ${ }^{6}$ published a book titled "Design of Multistory Reinforced Concrete Buildings for Earthquake Motions" that covered aspects of seismology, dynamics, and design of both reinforced concrete members and structural systems that are essential in earthquake-resistant design.

An important contribution of the book is the recognition that the shear demand imposed on members by earthquake motions are a function of the flexural strength of the member. This capacity design approach to calculating shear demands is shown in Fig. 4 (Fig. 6.1 in Ref. 6). The proposed approach included effects of gravity loads ( $W$ in Fig. 4) and assumed that moments develop at each end of a member $\left(M_{1}\right.$ and $M_{2}$ in Fig. 4) in response to earthquake motions that induce double curvature. Unlike today's practice, use of the nominal flexural strength, rather than the probable or expected strength, was recommended. 
For provision of transverse reinforcement, Blume, Newmark, and Corning recommended limiting the spacing of transverse hoops (referred to as stirrup-ties) to the lesser of one-half the effective depth $(d / 2), 16$ times the longitudinal bar diameter, and $12 \mathrm{in}$. (300 mm). It was also recommended to limit shear stress demands to below $6 \sqrt{f_{c}^{\prime}}[\mathrm{psi}]\left(0.5 \sqrt{f_{c}^{\prime}}[\mathrm{MPa}]\right)$ to avoid congestion of reinforcement. A decade later, experiments would demonstrate that limiting shear stress demands to below $6 \sqrt{f_{c}^{\prime}}$ [psi] $\left(0.5 \sqrt{f_{c}^{\prime}}\right.$ [MPa] $)$ is critical for delaying shear strength decay.

In contrast to the Blume, Newmark, and Corning book, the 1963 ACI Building Code ${ }^{7}$ did not include special provisions for members expected to undergo earthquake-induced deformations. In frames, nominal shear strength $\left(V_{n}\right)$ was calculated using Eq. 1, with an upper shear stress limit of $10 \sqrt{f_{c}^{\prime}}$ [psi] $\left(0.83 \sqrt{f_{c}^{\prime}}[\mathrm{MPa}]\right)$. Transverse reinforcement spacing was limited to one-half the effective depth $(d / 2)$ for shear stresses up to $6 \sqrt{f_{c}^{\prime}}$ [psi] $\left(0.5 \sqrt{f_{c}^{\prime}}\right.$ [MPa]) and onefourth the effective depth $(d / 4)$ for higher stress demands. Where compression reinforcement was required, stirrup/tie spacing was further limited to the lesser of 16 times the longitudinal bar diameter and 48 tie bar diameters.

$$
\begin{aligned}
& V_{n}=V_{c}+V_{s}=\left(1.9 \sqrt{f_{c}^{\prime}}+2500 \frac{\rho_{w} V d}{M}\right) b d+\frac{A_{v} f_{y} d}{S}[\mathrm{psi}] \\
& V_{n}=V_{c}+V_{s}=\left(0.16 \sqrt{f_{c}^{\prime}}+17 \frac{\rho_{w} V d}{M}\right) b d+\frac{A_{v} f_{y} d}{s}[\mathrm{MPa}]
\end{aligned}
$$

In Eq. $1, V_{c}$ and $V_{s}$ are the shear strength attributed to the concrete and transverse reinforcement, respectively, $f_{c}^{\prime}$ is the concrete compressive strength, $\rho_{w}$ is the longitudinal reinforcement ratio, $V$ and $M$ are the shear force and moment demand at the critical section, $b$ and $d$ are the width and effective depth of the member, $A_{v}$ and $f_{y}$ are the crosssectional area and yield strength of the transverse reinforcement, and $s$ is the spacing of transverse reinforcement.

\section{$\underline{\text { Subsequent studies }}$}

In the 1960s, studies investigating the effect of load reversals on the flexural strength of singly and doubly reinforced beams $s^{8,9}$, as well as single-bay frames ${ }^{10}$, supported previous findings that load reversals have a negligible impact on flexural strength. Shear mechanisms did not play a significant role in either study because the former (Ref. 8 and 9) focused on the constant moment region of beams subjected to 4-point loads, and the latter (Ref. 10) on highly slender specimens. In their report of the single-bay frame tests, Bertero and McClure did, however, emphasize the importance of suppressing non-ductile failure mechanisms related to instability, shear, and bond. The Bertero and McClure study also found that reversals of load can significantly degrade the stiffness of frame members, although their findings may have overstated the effect because significant degradation of the bond between reinforcing bars and concrete developed. The loss of bond, which contributed significantly to the loss of lateral stiffness, may have been exacerbated by the small scale of the test specimens (members had 2-7/8 by 4 in., or 72 by $100 \mathrm{~mm}$, cross-sections).

Tests were conducted in Japan to investigate the behavior of axially loaded members subjected to repeated displacement reversals ${ }^{11-13}$. Results showed that axial thrust must remain below the balanced point if member ductility is important. The tests also showed that, when subjected to cyclic displacement reversals, specimens can exhibit pinched hysteresis characterized by a region of low stiffness near the zero shear force axis. Furthermore, results from these tests indicated that shear-related mechanisms may become dominant and limit the deformability of the specimens if not adequately suppressed. To limit the influence of shear mechanisms, the researchers recommended a minimum shear span to depth ratio of 2 and a minimum transverse reinforcement ratio of $0.6 \%$ (as summarized in Ref. 14).

Among other findings, tests of seven beam-column connection subassemblies by Hanson and Conner ${ }^{15}$ clearly demonstrated the importance of hoops to both resist shear demands and provide confinement to the core of flexural members subjected to multiple displacement reversals.

\section{UNDERSTANDING AND MITIGATING SHEAR STRENGTH DECAY}

As described previously, early studies of the behavior of frame members under cyclic displacement reversals were aimed principally at understanding flexural response. To ensure a flexural failure mode, specimens were often designed with low shear stresses and provided with transverse reinforcement at least equal to that required to resist the entire shear demand. Nonetheless, Burns and Siess ${ }^{4}$ noted that the deformation capacity of flexural members subjected to displacement reversals could be limited by a "mode of failure involving shear" that developed after yielding of the flexural reinforcement. Several studies aimed at understanding this shear-related mode of failure were 
published in the early 1970s that significantly advanced the understanding of the role of shear in the response of flexural members subjected to cyclic displacement reversals.

Brown and Jirsa

Brown and Jirsa ${ }^{16-17}$ were perhaps the first to explicitly recognize the significant influence of shear strength decay on the load-deformation response of frame members. Their tests of reinforced concrete beams under cyclic displacement reversals showed that the "behavior of the specimens was influenced primarily by shear," and that "changes in geometry or load history which reduced the shear force or increased the shear capacity... significantly increased the... number of cycles to failure."

The test program consisted of twelve reinforced concrete beams cantilevered from a large concrete block at one end (Fig. 5). The beams had a 6 by 12 in. (150 by $300 \mathrm{~mm}$ ) cross-section, equal areas of longitudinal tension and compression reinforcement $\left(\rho_{w}\right.$ of either 0.015 or 0.026$)$, and No. $3(10 \mathrm{~mm})$ hoops with a spacing that varied among the specimens. Variables of interest included the effect of loading type (monotonic, unidirectional cycling, and reversed cycling), imposed displacement amplitude (either 5 or 10 times the yield deflection), hoop spacing, and shear stress level.

Although specimens subjected to monotonic and uni-directional cycling exhibited failure modes dominated by flexure, test results showed that the response of specimens to fully reversed cyclic loads was heavily influenced by shear demands. In Fig. 6, the load versus deflection responses of two similar specimens are plotted. The specimens were subjected to reversed cyclic displacements to approximately $11 \%$ drift and an approximate shear stress magnitude of either 200 or $400 \mathrm{psi}(1.4$ or $2.8 \mathrm{MPa})$. The difference in imposed shear stresses was a result of different shear spans (six and three times the effective depth, respectively), and not differences in specimen cross-section or reinforcement. In both cases, the shear strength provided by hoops (assuming a horizontal shear crack projection of $d$ ) exceeded the demand. As can be seen in Fig. 6, resistance to lateral loads degraded at a much greater rate in Specimen 88-34-RV1030 [Fig. 6(b)], than in Specimen 88-35-RV10-60 [Fig. 6(a)].

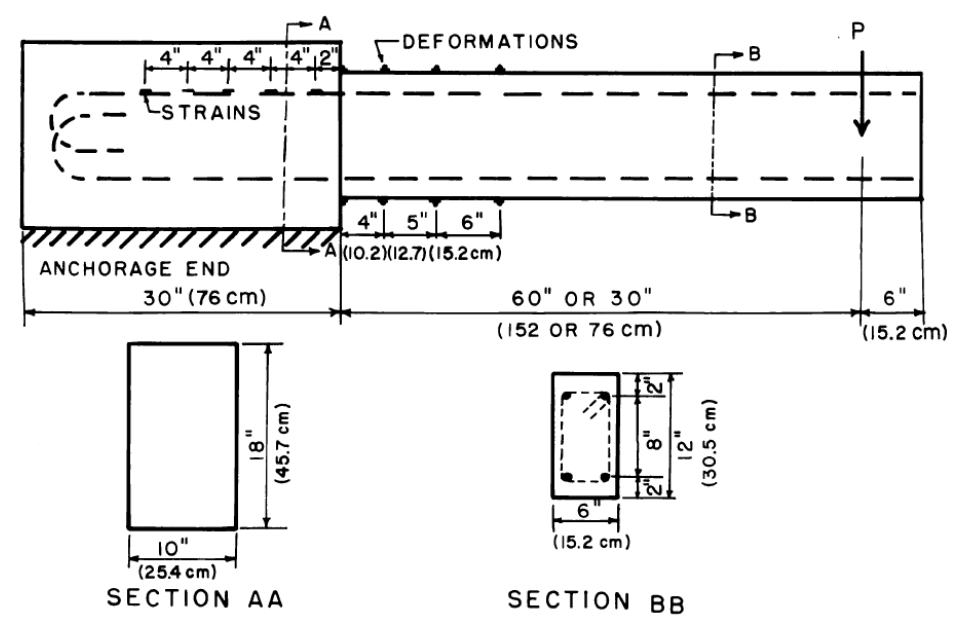

Figure 5 - Schematic of beam specimens tested by Brown and Jirsa (Ref. 17). 


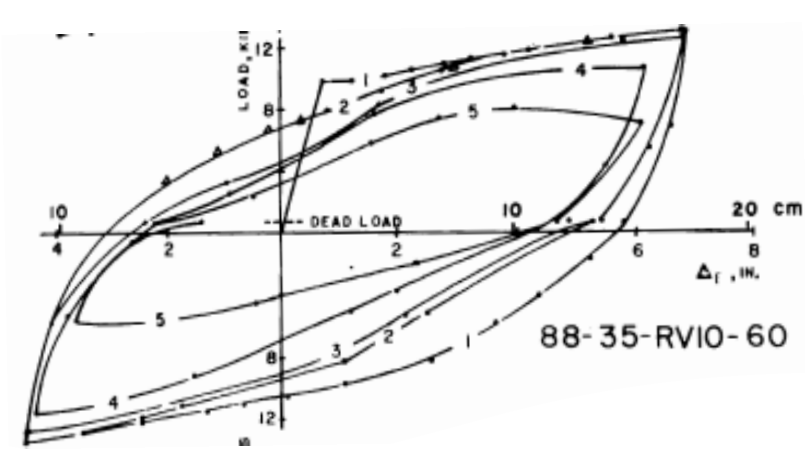

(a) Shear stress of $200 \mathrm{psi}(1.4 \mathrm{MPa})$

1 in. $\approx 1.7 \%$ chord rotation

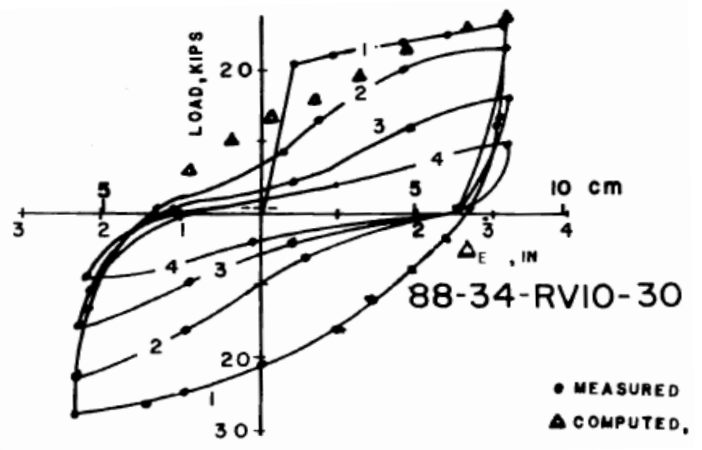

(b) Shear stress of $400 \mathrm{psi}(2.8 \mathrm{MPa})$

1 in. $\approx 3.3 \%$ chord rotation

Figure 6 - Load versus deflection response of beams subjected to cyclic displacement reversals (Ref. 17), 1 kip $=4.45 \mathrm{kN}, 1$ in. $=25 \mathrm{~mm}$.

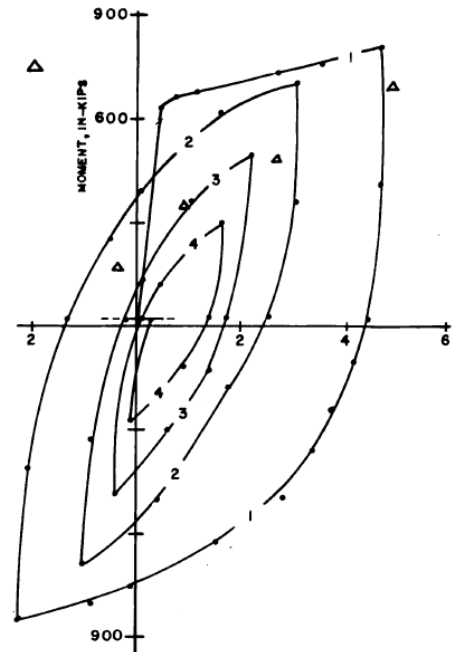

Figure 7 - Moment versus rotation response of beam subjected to cyclic displacement reversals (Ref. 17), 100 in.-kip $=11.3 \mathrm{~m}-\mathrm{kN}$.

The importance of shear-related mechanisms in the strength decay observed in the test of Specimen 88-34-RV10-30 is further illustrated in Fig. 7, which shows the moment developed at the support face plotted versus measured rotation. That the measured rotations decreased significantly while imposed deflections remained approximately constant (Fig. 6(b)) is evidence of the increasingly dominant role of shear deformations late in the test. The authors attributed this strength decay to "abrasion over a surface formed by a combination of diagonal tension cracks and nearly vertical flexural tension cracks resulting from load reversals.”

Brown and Jirsa concluded that larger deformation demands and reductions of the shear span (and thus increases in shear demand) resulted in a smaller number of cycles sustained prior to failure. To mitigate these effects, they showed that "reducing the stirrup spacing increased significantly the number of cycles to failure." In addition, the authors noted that pinching of the hysteresis near zero load, as is evident in Fig. 6(b), "was the result of shear deformations and of a reduced stiffness during closure of flexural cracks formed in the previous half-cycle." 


\section{Wight and Sozen}

Shear strength decay under reversals of load was studied by Wight and Sozen ${ }^{14,18}$ in members with and without axial thrust. A series of twelve specimens was tested using the setup shown in Fig. 8. An axial load of between zero and one-half of the calculated balanced load was applied and held constant throughout each test. Lateral loads were applied with hydraulic rams at each end of the specimen in opposite directions, such that a reversal of moment developed across the central stub.

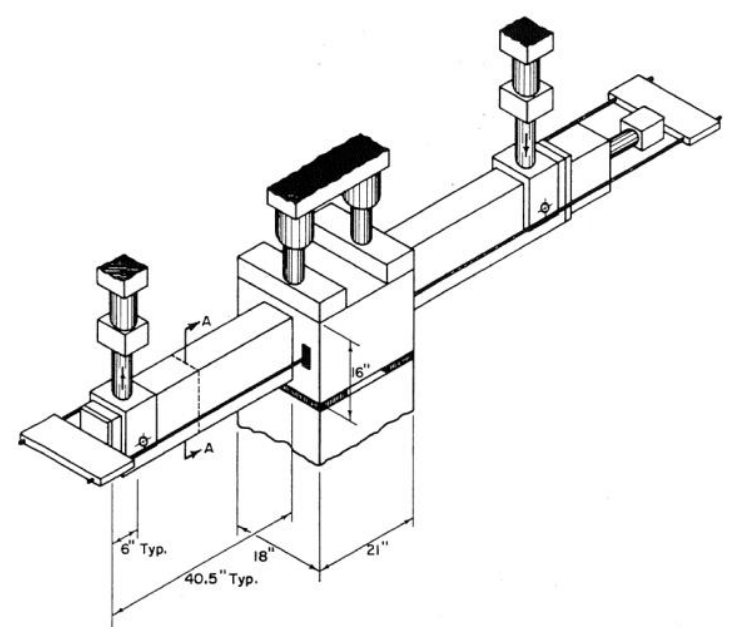

Figure 8 - Schematic of test setup used by Wight and Sozen (Ref. 18), 1 in. $=25 \mathrm{~mm}$.

An important feature of the test program was that the shear capacity, calculated as the sum of terms representing contributions from the concrete and transverse reinforcement (Eq. 2), varied between 1 and 3 times the expected demand. Relatively high shear stresses, on the order of $6 \sqrt{f_{c}^{\prime}}$ [psi] $\left(0.5 \sqrt{f_{c}^{\prime}}[\mathrm{MPa}]\right)$, were imposed.

$$
\begin{gathered}
V_{n}=V_{c}+V_{s}=2.0\left(1+0.0005 \frac{N_{u}}{A_{g}}\right) b d \sqrt{f_{c}^{\prime}}+\frac{A_{v} f_{y} d}{S}[\mathrm{psi}] \\
V_{n}=V_{c}+V_{s}=0.17\left(1+0.0005 \frac{N_{u}}{A_{g}}\right) b d \sqrt{f_{c}^{\prime}}+\frac{A_{v} f_{y} d}{s}[\mathrm{MPa}]
\end{gathered}
$$

In Eq. 2, the terms are defined as in Eq. 1, except $N_{u}$ is the axial thrust and $A_{g}$ is the gross cross-sectional area.

Results from three of the tests are shown in Fig. 9, plotted as shear force versus deflection. The curves represent specimens with an axial load of $40 \mathrm{kip}\left(180 \mathrm{kN}\right.$, or approximately $\left.0.1 A_{g} f_{c}^{\prime}\right)$ and varied amounts of transverse reinforcement. The top curve resulted from the test of a specimen that had a shear capacity, calculated using Eq. 2, that was approximately equal to the expected demand. It is clear that shear decay played a dominant role in the response of the specimen, which lost half its capacity after three cycles at a chord rotation of approximately $2.5 \%$, or 1 in. $(25 \mathrm{~mm})$ of deflection. The specimen represented by the middle curve fared somewhat better, although shear strength decay was still a dominant feature of the response. This specimen had transverse reinforcement provided to carry $70 \%$ of the expected capacity, resulting in a calculated nominal shear strength (Eq. 2) that was 1.2 times the expected demand. The third curve shown resulted from the test of a member that had a nominal shear strength that was 2.5 times the expected demand ( $V_{S}$ alone was approximately twice the demand). This specimen exhibited little shear decay after several loading cycles to a chord rotation of approximately $5 \%$, or a deflection of $2 \mathrm{in}$. (50 mm), as indicated by strength retention and minimal pinching of the hysteresis. These results show the important correlation between amount of transverse reinforcement $\left(V_{s} / V_{u}\right)$ and shear strength degradation. Other results, not shown here, indicated that the "decay in shear strength is less in elements with higher axial loads, everything else being equal." However, this finding is limited to members that, like the test specimens, are subjected to axial thrusts with a magnitude that is less than the balanced load. 


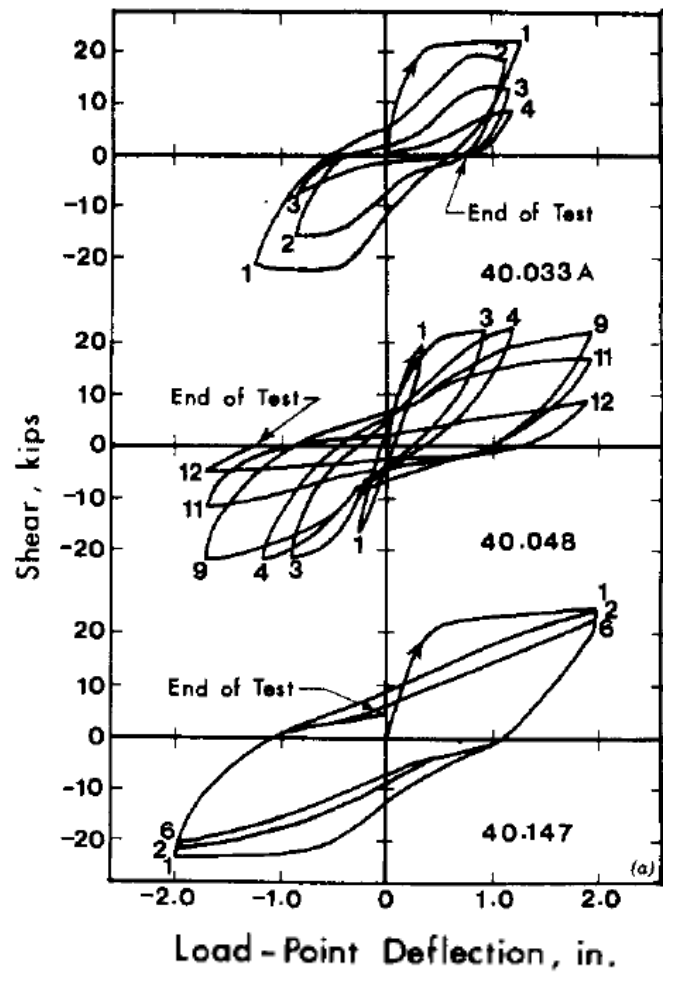

Figure 9 - Load versus deflection response of columns subjected to cyclic displacement reversals (Ref. 14), 1 kip $=4.45 \mathrm{kN}, 1$ in. $=25 \mathrm{~mm} \approx 2.5 \%$ chord rotation.

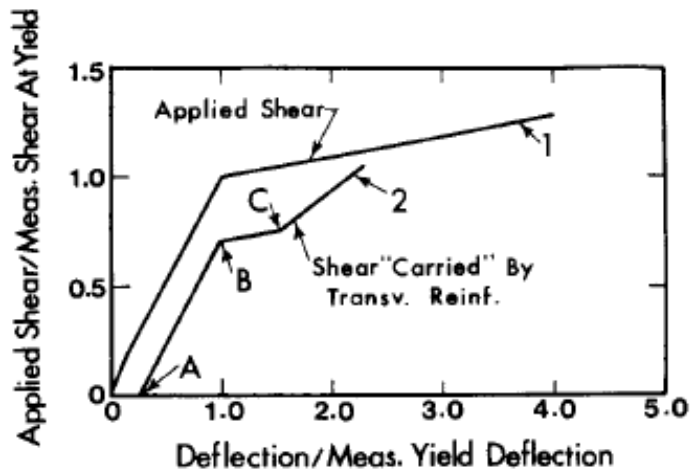

Figure 10 - Illustration of shear force versus deflection (Ref. 14).

Through observations and measurements, Wight and Sozen described the mechanisms that contribute to shear strength decay. Cracking and spalling caused by repeated reversals of load compromise the ability of the compression zone to transfer shear. Fig. 10, which qualitatively shows the shear demand and resistance to shear plotted versus displacement ductility, indicates a shift in shear resistance mechanisms towards one dominated by truss action. Because the ability of the specimen to resist shear in excess of that carried by hoops diminishes, they recommended that "if reinforced concrete elements are designed to resist earthquake effects by energy dissipation in the inelastic range, the transverse reinforcement must be designed to carry the entire shear."

Furthermore, Wight and Sozen showed that "use of closely spaced hoops designed to carry all of the shear does not necessarily prevent shear failures." Because hoops are effective in resisting shear only because they form part of a truss mechanism, "all of the loads applied to a reinforced concrete members are ultimately carried by the concrete and 
if the concrete does not stay intact, the strength of the reinforcement cannot be developed." Wight and Sozen recommended limiting the spacing of hoops to no more than one-fourth of the effective depth, and designing members so as to prevent yielding of the transverse reinforcement. If the hoops yield, "the concrete section... becomes distorted. As a result, the shear strength decays."

\section{Popov, Bertero and Krawinkler}

Popov, Bertero and Krawinkler ${ }^{19}$ also addressed the shear strength decay phenomenon in a study of RC beams under large reversals of load. Fig. 11 shows results from two beam specimens, plotted as applied load versus deflection. Both specimens were subjected to relatively high shear stress demands of 5 to $6 \sqrt{f_{c}^{\prime}}$ [psi] ( 0.42 to $0.50 \sqrt{f_{c}^{\prime}}$ [MPa]). Beam 35 was reinforced so that the calculated nominal shear strength (Eq. 2, with $N_{u}=0$ ) was approximately equal to the shear demand. The specimen failed abruptly with a mode described as "predominantly of a shear diagonal tension type... [that] occurred after some flexural yielding developed." Beam 43 which was reinforced so that the calculated shear strength provided by stirrups alone exceeded the demand by $25 \%$, exhibited little decay in shear strength despite multiple reversals of load to a tip deflection exceeding $3 \mathrm{in}$., or $75 \mathrm{~mm}$ (chord rotations of approximately 4\%). These findings support neglecting the contribution of the concrete when calculating the nominal shear strength in regions of members expected to undergo multiple large reversals of load.

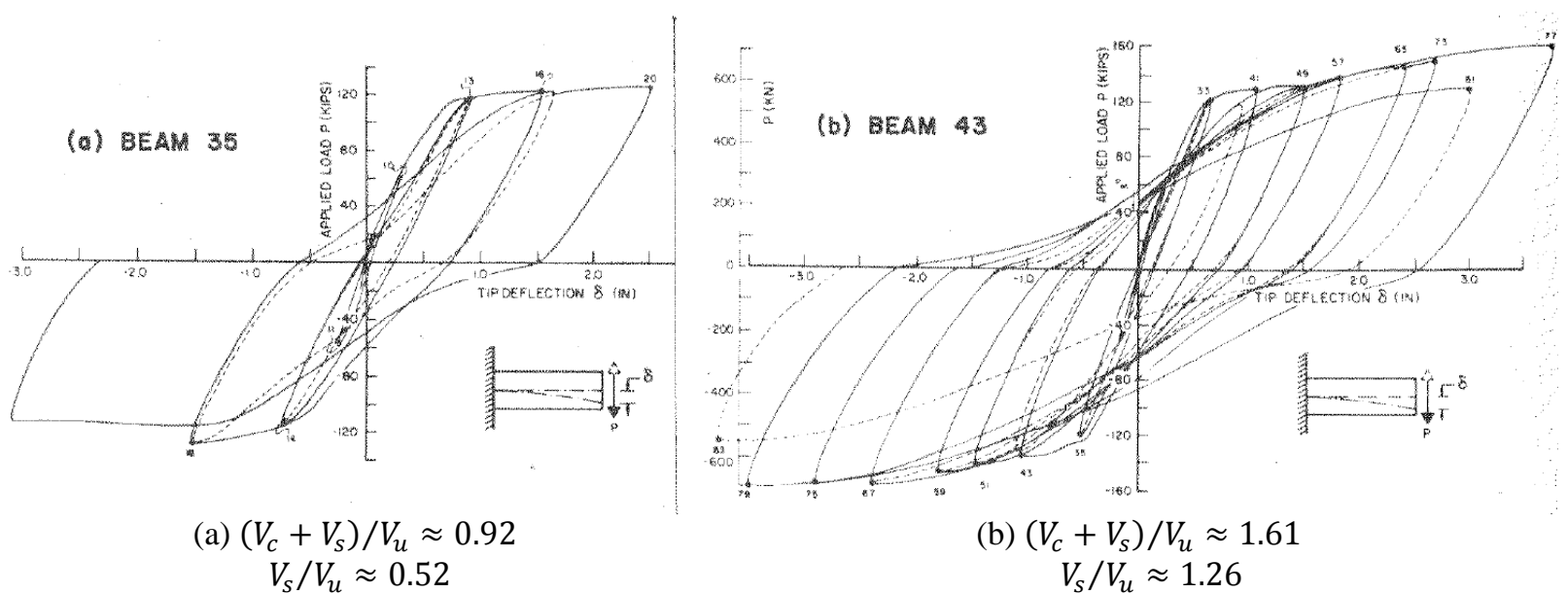

Figure 11 - Load versus deflection response of beams subjected to cyclic displacement reversals (Ref. 20), 1 kip $=4.45 \mathrm{kN}, 1$ in. $=25 \mathrm{~mm} \approx 1.3 \%$ chord rotation.

Closer evaluation of the results from Beam 43 shows that some pinching of the hysteresis developed at larger chord rotations. This was associated with "considerable grinding of the aggregate and mortar... along the two main diagonal cracks," leading to a sliding shear failure. In either specimen, it was shown that shear distortion may be an important deformation component after multiple reversals of load.

Popov, Bertero and Krawinkler also noted that shear decay can be significant in members under shear stress demands of $6 \sqrt{f_{c}^{\prime}}$ [psi] $\left(0.5 \sqrt{f_{c}^{\prime}}[\mathrm{MPa}]\right)$, which is significantly less than the upper limit of $10 \sqrt{f_{c}^{\prime}}$ [psi] $\left(0.83 \sqrt{f_{c}^{\prime}}[\mathrm{MPa}]\right)$ permitted in design. They recommended limiting shear stress demands in regions of members expected to undergo multiple displacement reversals to no more than $6 \sqrt{f_{c}^{\prime}}$ [psi] $\left(0.5 \sqrt{f_{c}^{\prime}}[\mathrm{MPa}]\right)$. 


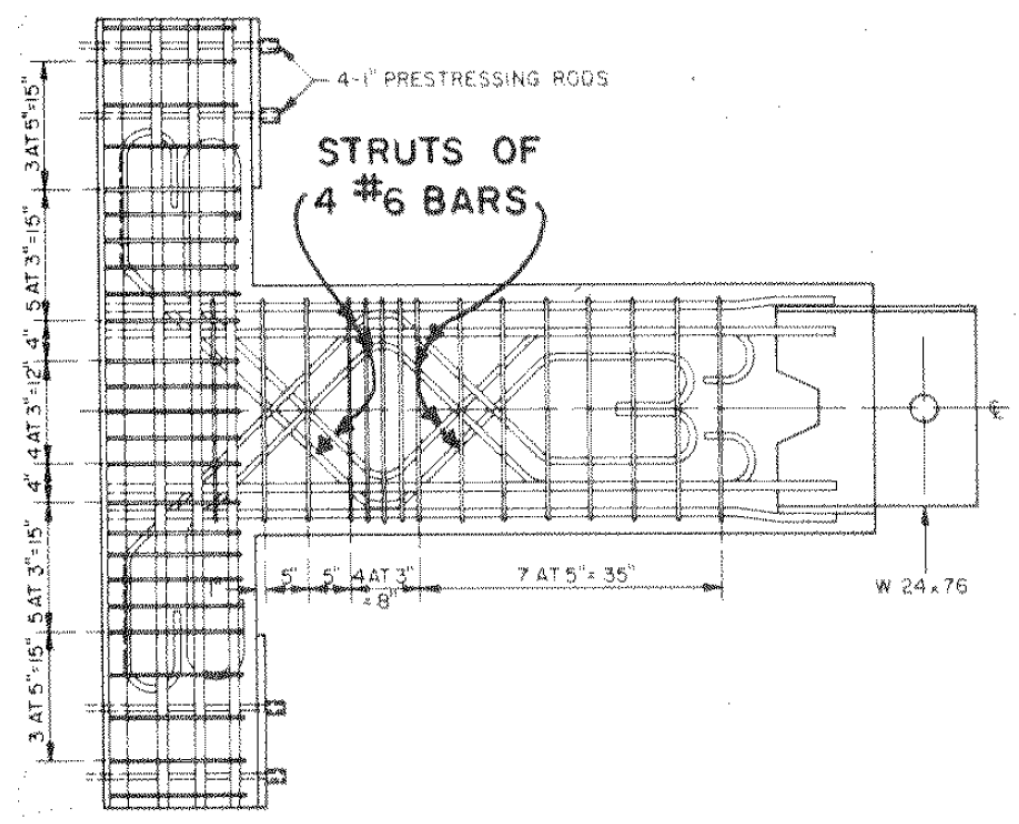

Figure 12 - Beam specimens tested by Bertero and Popov (Ref. 20), 1 in. $=25 \mathrm{~mm}$.

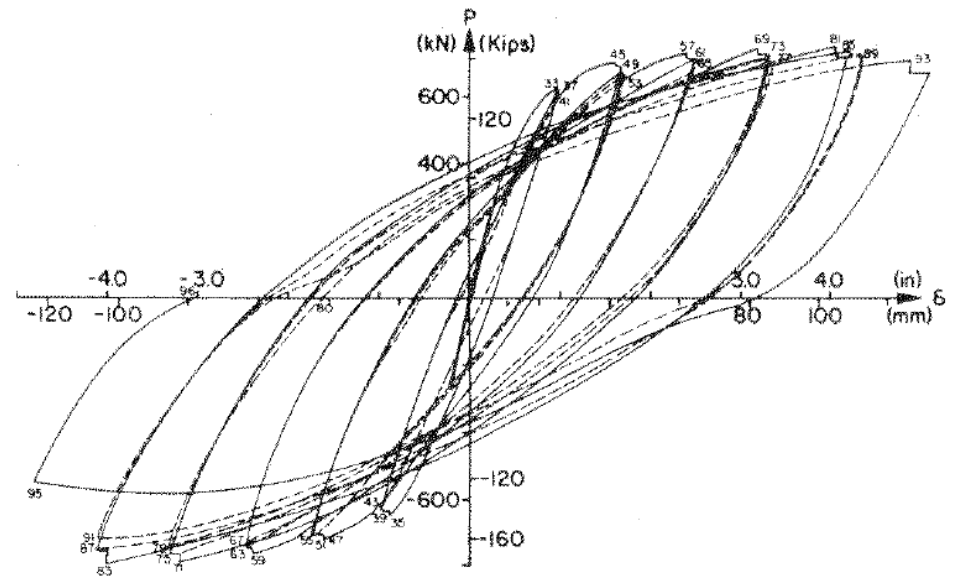

Figure 13 - Load versus deflection response of a diagonally reinforced beam (Ref. 20), 1 in. $=1.3 \%$ chord rotation.

In subsequent studies, Bertero and Popov ${ }^{20}$ showed that diagonally oriented reinforcement in the expected plastic hinging region of beams can significantly improve the response to repeated reversals of load. This finding followed tests conducted in New Zealand that showed the significant benefit derived from diagonally oriented reinforcement in coupling beams ${ }^{21}$. A diagram of one of the specimens tested by Bertero and Popov is shown in Fig. 12. The test result is shown in Fig. 13 as a plot of force versus deflection. The excellent deformation capacity (approximately 5\% chord rotation) and full hysteresis with no pinching until the last few loading cycles are evidence that shear strength decay mechanisms, including sliding, were significantly delayed (or prevented) by the diagonal reinforcement. Although highly effective, this reinforcement layout would be difficult to construct. 
$\underline{\text { Scribner and Wight }}$

Through tests of fourteen beam-column connection subassemblies, Scribner and Wight ${ }^{22-23}$ investigated the effect of shear stress demand on shear strength decay and evaluated the effectiveness of intermediate longitudinal reinforcement as a means of delaying strength decay. A diagram of a test specimen is shown in Fig. 14. Among the specimens, the shear span length was varied along with both longitudinal and transverse reinforcement amounts, resulting in average shear stress demands that ranged between approximately 2 and $6 \sqrt{f_{c}^{\prime}}$ [psi] ( 0.17 and $0.5 \sqrt{f_{c}^{\prime}}$ [MPa]). In addition, half of the specimens had intermediate depth longitudinal reinforcement (shown as a dashed line in Fig. 14) with an area that was approximately one-fourth of the flexural tension reinforcement area.

Test results indicated that when shear stress demands were less than $3 \sqrt{f_{c}^{\prime}}$ [psi] $\left(0.25 \sqrt{f_{c}^{\prime}}\right.$ [MPa]), specimens "responded primarily in flexure with little tendency to lose shear strength or develop planes of shear slippage." Confirming previous findings ${ }^{18,20}$, Scribner and Wight noted that when shear stress demands exceeded $6 \sqrt{f_{c}^{\prime}}$ [psi] $\left(0.5 \sqrt{f_{c}^{\prime}}[\mathrm{MPa}]\right)$, members "experienced severe strength loss and loss of energy dissipation capacity due to planes of shear slippage which formed along cracks in regions of inelastic bending." A more modest influence of shear strength decay was observed in specimens subjected to shear stresses between 3 and $6 \sqrt{f_{c}^{\prime}}$ [psi] $\left(0.25\right.$ and $0.5 \sqrt{f_{c}^{\prime}}$ [MPa]).

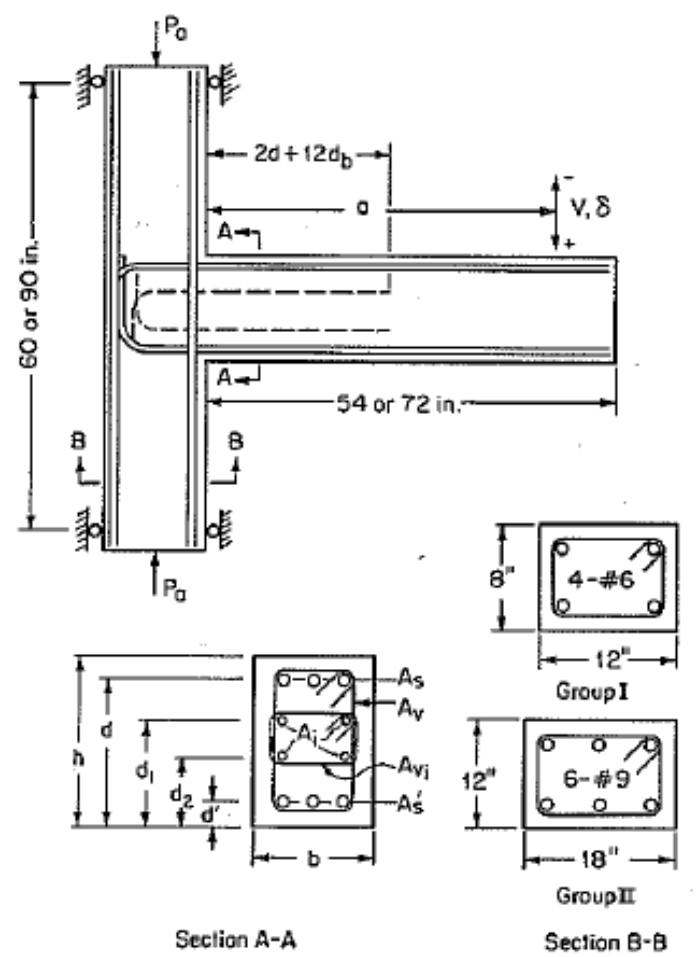

Figure 14 - Beam specimens tested by Scribner and Wight (Ref. 23), 1 in. $=25 \mathrm{~mm}$. 


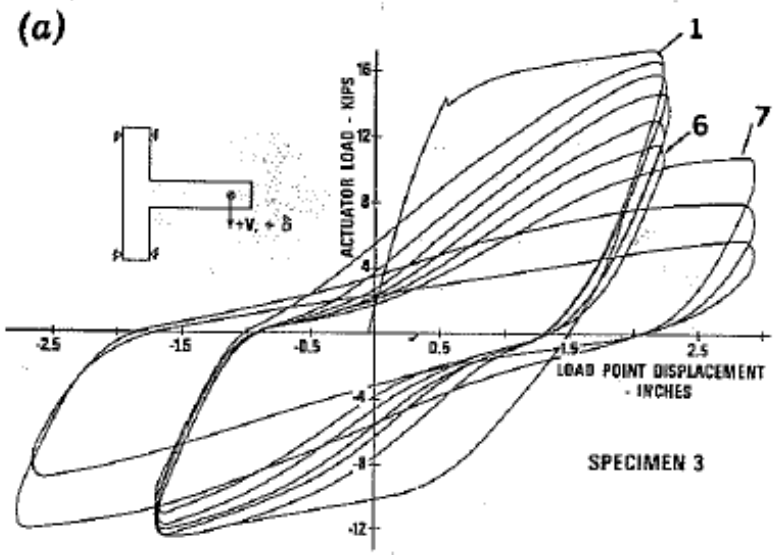

(a) No intermediate-depth longitudinal bars

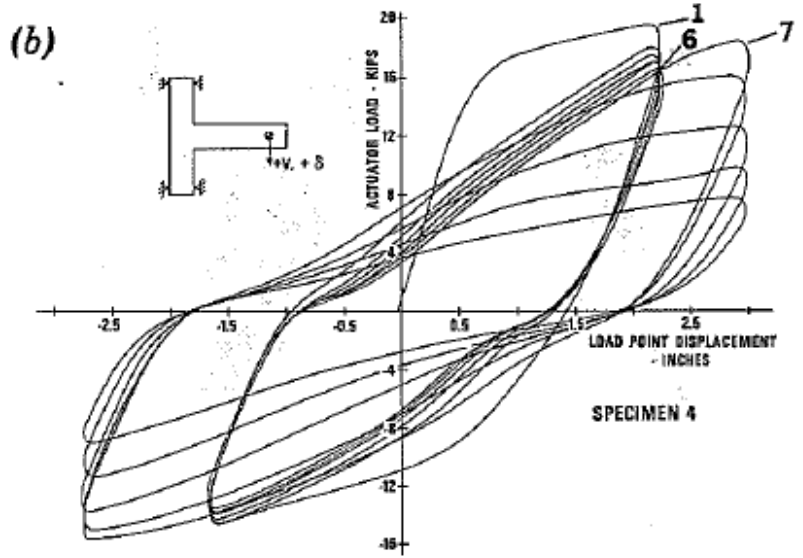

(b) Intermediate-depth longitudinal bars

Figure 15 - Load versus deflection response of beams subjected to cyclic displacement reversals (Ref. 23), $1 \mathrm{kip}=4.45 \mathrm{kN}, 1 \mathrm{in} .=25 \mathrm{~mm} \approx 2.4 \%$ chord rotation.

Intermediate depth longitudinal reinforcement was shown to be an effective means of delaying shear strength decay because it has a tendency to spread damage throughout the plastic hinging region of the beam. The improvement is shown in Fig. 15, which shows results from two different specimens plotted as load versus load point displacement. The plot in Fig. 15(a) resulted from the test of a specimen with no intermediate-depth reinforcement that was subjected to a shear stress demand of $3 \sqrt{f_{c}^{\prime}}$ [psi] $\left(0.25 \sqrt{f_{c}^{\prime}}\right.$ [MPa]), whereas the plot in Fig. 15(b) represents a specimen that had intermediate depth longitudinal reinforcement and was subjected to a shear stress demand of $3.5 \sqrt{f_{c}^{\prime}}$ [psi] $\left(0.29 \sqrt{f_{c}^{\prime}}[\mathrm{MPa}]\right)$. It is evident from Fig. 15 that use of intermediate depth longitudinal reinforcement effectively delayed shear strength decay, resulting in more loading cycles and larger displacements before a significant decay in strength occurred. Intermediate depth reinforcement was shown to be particularly effective in members with shear stress demands between 3 and $6 \sqrt{f_{c}^{\prime}}$ [psi] $\left(0.25\right.$ and $\left.0.5 \sqrt{f_{c}^{\prime}}[\mathrm{MPa}]\right)$.

\section{FROM RESEARCH TO PRACTICE - 1983 ACI BUILDING CODE}

In response to the growing body of evidence, ACI Committee 318 incorporated several changes into Appendix A of the 1983 Building $\operatorname{Code}^{2}$ aimed at reducing the potential for shear decay to limit the deformation capacity of frame members. The following were among the changes made:

- Shear Strength Calculation: The 1983 Building Code was the first edition to require that the contribution of concrete to the calculated shear strength of members with axial compressive forces less than $A_{g} f_{c}^{\prime} / 20$ be neglected $\left(V_{c}=0\right)$. It was permitted to attribute shear strength to the concrete when designing other members, including columns and walls.

- Hoop Detailing: In beams, hoops were required in potential plastic hinge regions (defined as being within a distance of two times the height of the member, $2 h$, from the face of a support) at a spacing that did not exceed the lesser of one-fourth the effective depth $(d / 4)$, eight times the diameter of the longitudinal reinforcement, 24 times the diameter of the transverse hoops, and 12 in. $(300 \mathrm{~mm})$. In addition, the 1983 ACI Building Code was the first edition to require that, at a minimum, every other longitudinal bar be supported by transverse reinforcement in regions were plasticity is expected to develop. Additional requirements (omitted here) applied to frame members supporting axial thrust.

- Capacity design: In $1971^{24}$, an appendix was added to the ACI Building Code that included provisions for seismic design. Among those provisions was the requirement that "web reinforcement shall be provided to develop shears resulting from factored gravity loads on members and from moment strengths of plastic hinges at ends of members produced by lateral displacements." It was permitted to assume that the moment strength of the plastic hinge was 
equal to the calculated nominal moment strength. The 1983 ACI Building Code was the first edition to require that the probable moment capacity, calculated assuming a reinforcement stress of at least $1.25 f_{y}$, be used to determine the shear demand in frame members located in regions of high seismic risk.

Collectively, these changes reduced the likelihood that transverse reinforcement would yield in beams subjected to cyclic displacement demands. Even if the transverse reinforcement yields, these changes ensured there would be significantly more confinement of the member core than before. Experimental data indicated that such changes would improve the deformation capacity of members and reduce the extent of damage expected to develop in response to seismically induced demands. These provisions remain in the current ACI Building Code with minor modifications (in 2014, the maximum hoop spacing in beams of special moment frames is limited to the lesser of one-fourth the effective depth $(d / 4)$, six times the diameter of the longitudinal reinforcement, and 6 in., or $150 \mathrm{~mm}$ ).

\section{SUMMARY}

Early research on the behavior of frame members subjected to cyclic displacement reversals was reviewed, with an emphasis on findings related to shear strength decay. The scope of the review ended with the 1983 ACI Building Code, which was the first edition of the ACI Code to include several provisions aimed at mitigating shear strength decay in flexural members. The following is a summary of major findings.

- Reduced member strength, pinching of the hysteresis, and an increase in the contribution of shear sliding and distortion to overall member deformation were found to indicate a decay in shear strength under reversals of load. Even if strength is maintained, it has been shown that shear mechanisms can contribute significantly to overall member deformation.

- Closely spaced hoops with sufficient strength to resist probable shear demands reduce the influence of shear strength decay on member behavior. However, "the use of closely spaced stirrups that are designed to carry all of the shear does not necessarily prevent shear failures." 14 This is because "all of the loads applied to a reinforced concrete member are ultimately carried by the concrete and if the concrete does not stay intact, the strength of the reinforcement cannot be developed." ${ }^{14}$ Confinement of the core of the member is therefore essential to minimizing the influence of shear decay mechanisms.

- Shear stress demand is a primary factor governing shear strength decay. Provided there is adequate transverse reinforcement, the behavior of members with shear stresses below $3 \sqrt{f_{c}^{\prime}}$ [psi] $\left(0.25 \sqrt{f_{c}^{\prime}}\right.$ [MPa] $)$ will experience little or no shear strength decay. It is likely that shear strength decay will be an important feature of the response to cyclic displacements in members subjected to shear stress in excess of $6 \sqrt{f_{c}^{\prime}}$ [psi] $\left(0.5 \sqrt{f_{c}^{\prime}}[\mathrm{MPa}]\right)$, even when a significant amount of transverse hoops is provided at a close spacing.

- The number of loading cycles and magnitude of the displacement demand tend to increase the likelihood that shear strength decay will influence the response, whereas moderate levels of axial load (less than the balanced load) tend to reduce shear strength decay.

- Inclined reinforcement located within the expected plastic hinging region has been shown to delay or prevent shear sliding and strength decay. Likewise, intermediate depth longitudinal reinforcement with an area that is approximately one-fourth of the area of flexural tension reinforcement has been shown to delay shear strength decay by spreading damage and delaying localization of distress.

\section{ACKNOWLEDGEMENTS}

The writers would like to acknowledge the significant contributions of James K. Wight to the understanding of behavior and design of reinforced concrete structures. Through his research and service, Jim has helped shape current design practice. Through his teaching and mentorship, he has furthered the development of both students and colleagues. The writers are grateful to consider him a colleague and a friend. 


\section{REFERENCES}

1. ACI Committee 318, (2014), "Building Code Requirements for Structural Concrete (ACI 318-14) and Commentary," American Concrete Institute, Farmington Hills, MI, 519 pp.

2. ACI Committee 318, (1983), "Building Code Requirements for Reinforced Concrete (ACI 318-83)," American Concrete Institute, Detroit, MI, 111 pp.

3. McCollister, H.M., Siess, C.P., and Newmark, N.M., (1954), "Load-Deformation Characteristics of Simulated Beam Column Connections in Reinforced Concrete," Structural Research Series No. 76, University of Illinois, Urbana, Illinois, $172 \mathrm{pp}$.

4. Burns, N.H., and Siess, C.P., (1962), "Load-Deformation Characteristics of Beam-Column Connections in Reinforced Concrete," Structural Research Series No. 234, University of Illinois, Urbana, Illinois, 272 pp.

5. Burns, N.H., and Siess, C.P., (1966), "Repeated and Reversed Loading in Reinforced Concrete," Journal of the Structural Division, Proceedings of the American Society of Civil Engineers, 92(ST5), 65-78.

6. Blume, J.A., Newmark, N.M., and Corning, L.H., (1961), Design of Multistory Reinforced Concrete Buildings for Earthquake Motions, Portland Cement Association, Skokie, Illinois.

7. ACI Committee 318, (1963), "Building Code Requirements for Reinforced Concrete (ACI 318-63)," American Concrete Institute, Detroit, MI, 144 pp.

8. Sinha, B.P., Gerstle, K.H., and Tulin, L.G., (1964), "Response of Single Reinforced Beams to Cyclic Loading," Journal of the American Concrete Institute, 61(8), 1021-1038.

9. Agrawal, G.L., Tulin, L.G., and Gerstle, K.H., (1965), "Response of Doubly Reinforced Beams to Cyclic Loading," Journal of the American Concrete Institute, 62(7), 823-835.

10. Bertero, V.V. and McClure, G., (1964), "Behavior of Reinforced Concrete Frames Subjected to Repeated Reversible Loads," Journal of the American Concrete Institute, 61(10), 1305-1330.

11. Aoyama, H. (1965), "Moment-Curvature Characteristics of Reinforced Concrete Members Subjected to Axial Load and Reversal of Bending," ACI Special Publication No. 12, p 183-212.

12. Ikeda, A., (1968), "Load-Deformation Characteristics of Reinforced Concrete Columns Subjected to Alternating Loading," Report of the Training Institute for Engineering Teachers, Yokohama National University.

13. Kanoh, Y., et al., (1969), "Shear Strength of Reinforced Concrete Beams Under Many Cyclic Alternate Loading," Research Report of A.I.J.

14. Wight, J.K. and Sozen, M.A., (1975), "Strength Decay of RC Columns under Shear Reversals," Journal of the Structural Division, Proceedings of the American Society of Civil Engineers, 101(ST5), 1053-1065.

15. Hanson, N.W. and Conner, H.W., (1967), "Seismic Resistance of Reinforced Concrete Beam-Column Joints," Journal of the Structural Division, Proceedings of the American Society of Civil Engineers, 93(ST5), 533-560.

16. Brown, R.H., (1970), "Reinforced Concrete Beams under Slow Cyclic Loadings," PhD Thesis, Civil Engineering Department, Rice University.

17. Brown, R.H. and Jirsa, J.O., (1971), "Reinforced Concrete Beams under Load Reversals," Journal of the American Concrete Institute, 68(5), 380-390.

18. Wight, J.K. and Sozen, M.A., (1973), "Shear Strength Decay in Reinforced Concrete Columns Subjected to Large Deflection Reversals," Structural Research Series No. 403, University of Illinois, Urbana, Illinois, 312 pp.

19. Popov, E.P., Bertero, V.V., and Krawinkler, H., (1972), "Cyclic Behavior of Three Reinforced Concrete Flexural Members with High Shear," Report No. EERC 72-5, University of California, Berkeley, 78 pp.

20. Bertero, V.V. and Popov, E.P., (1975), "Hysteretic Behavior of Reinforced Concrete Flexural Members with Special Web Reinforcement," Proceedings of the U.S. National Conference on Earthquake Engineering, p. 316326.

21. Paulay, T. and Binney, J.R., (1974), "Diagonally Reinforced Coupling Beams of Shear Walls," ACI Special Publication No. 42, Shear in Reinforced Concrete, V. 2, Detroit, Michigan, p. 579-598.

22. Scribner, C.F. and Wight, J.K., (1978), "Delaying Shear Strength Decay in Reinforced Concrete Flexural Members under Large Load Reversals," Report UMEE 78R2, University of Michigan, Ann Arbor, Michigan, 246 pp.

23. Scribner, C.F. and Wight, J.K., (1980), "Strength Decay in R/C Beams under Load Reversals," Journal of the Structural Division, Proceedings of the American Society of Civil Engineers, 106(ST4), 861-876.

24. ACI Committee 318, (1971), "Building Code Requirements for Reinforced Concrete (ACI 318-71)," American Concrete Institute, Detroit, MI, 78 pp. 